\title{
Journal of Pregnancy and Child

\section{The Incidence of Exposure to Antibiotics in Children Less Than 6 Years of Age: A Survey in a Portuguese Metropolitan Area}

Humberto S Machado ${ }^{1,2,4^{*}}$, Ana Sofia Marafona ${ }^{2}$, Joana Patrícia Meireles ${ }^{2}$, Catarina S Nunes ${ }^{1,3,4}$, Ana Laura Esteves ${ }^{2}$, Sofia Marques ${ }^{2}$, Bruno Bragança ${ }^{2}$, Daniela Bento ${ }^{2}$, Diana Brites ${ }^{2}$, Fátima Costa ${ }^{2}$, Filipa Andrade ${ }^{2}$, Guida Maria Santos ${ }^{2}$, Márcia Vieira-Coimbra ${ }^{2}$ and Sofia Pereira ${ }^{2}$

${ }^{1}$ Anesthesiology Service, Porto Hospital Center, Porto, Portugal

2Institute of Biomedical Sciences Abel Salazar, University of Porto, Porto, Portugal

3 Open University, Department of Science and Technology, Delegation of Porto, Portugal

${ }^{4}$ Centre of Clinical Research in Anaesthesiology, Centro Hospitlar do Porto, Porto, Portugal

*Corresponding author: Humberto S Machado, Anaesthesiology Service, Porto Hospital Center, Porto, Portugal, Tel: 351935848475; E-mail: hjs.machado@gmail.com Received date: September 15, 2016; Accepted date: October 28, 2016; Published date: October 31, 2016

Copyright: (c) 2016 Machado HS, et al. This is an open-access article distributed under the terms of the Creative Commons Attribution License, which permits unrestricted use, distribution and reproduction in any medium, provided the original author and source are credited.

\begin{abstract}
Background: The contact with antibiotics at an early age may lead to a number of nefarious consequences. Nevertheless, the amount of literature available on the usage of antibiotics in children is scarce. Taking into account the increasing emergence of resistant bacterial strains, it is imperative to study and make society aware of the excessive exposure of children to antibiotics. The purpose of this study was to evaluate the incidence of antibiotic therapy in children under the age of six, in the metropolitan area of Oporto.
\end{abstract}

Methods: Surveys (concerning children born in the metropolitan area of Oporto since 2010) were conducted in several nursery schools, and its answers $(n=1031)$ were subsequently analysed. Our primary outcome was the incidence of exposure to antibiotics in children under 6 years of age in the metropolitan area of Oporto. Statistical significance was set as a $\mathrm{p}$ value inferior to 0.05 .

Results: We verified that 958 children (92.9\%) were exposed to antibiotics before the age of six. Additionally, five associations were found between the considered variables: cessation of treatment and number of times the child has resorted to antibiotics in his/her lifetime $(p<0,0001)$; cessation of treatment and average of intake per year $(p=0,021, R=0,082)$; child with chronic disease and number of times of usage during his/her lifetime $(p=0,02)$; eldest child's age and cessation of treatment $(p=0,018)$; eldest child's age and number of times of usage during the child's lifetime $(p=0,014, R=0,096)$.

Conclusion: Our study revealed that the exposure to antibiotics in children under six years of age is exceptionally high. Furthermore, the presence of chronic disease seems to be associated with a higher frequency of antibiotic intake. Couples with older children had better antibiotic therapy compliance, as well as higher frequency of antibiotic intake.

Keywords: Antibiotics exposure; Children antibiotic treatment; Oporto children antibiotic treatment

\section{Introduction}

The era of antibiotics began in 1940, after the introduction of penicillin as a medical therapy [1]. It enabled the eradication of many bacterial-related pathological conditions linked to enormous rates of morbidity and mortality, with a significant decrease in child mortality since then.

Given its significance in current medical practices, antibiotics must be cautiously used because, unlike other medications, its systematic usage will gradually lead to a reduction of its effectiveness. Despite being a natural consequence of antibiotic therapy, resistance to this type of drugs has been growing [2]. A responsibility for increasing resistances has been attributed to an also increasingly easier access to this medication; in addition, this induced a more frequent prescription, most of the times by less informed health practitioners and hence a wider usage in a larger range of infectious conditions [3].
All these sequential facts had favoured the development of microbial strains resistant to the most commonly used antibiotics [2]. This upsurge of resistance is a proven fact, shown by its emergence at an earlier age [3], as is the adequacy of the therapeutic decision the current concern of physicians [4]. Simultaneously, there has been a distinct reduction in production of new classes of antimicrobial drugs. The combination of these conditions has contributed to a progressively increased difficulty in treating certain types of infections [2].

In order to avoid treatment failure in infections supposedly caused by resistant bacteria, large spectrum antibiotic therapy has been appointed as the therapeutic scheme of choice. Nevertheless, this form of action has facilitated the increase of antibiotic selective pressure and development of new bacterial resistances, which are harder to overcome. Therefore, the only way to break this cycle is to encourage a sensible use of antibiotics [2].

Furthermore, the implications of premature exposure to antimicrobial drugs go beyond the development of resistance, ranging from alteration of the intestinal microbiome, leading to a potential 
intestinal inflammatory disease [5], to association with childhood obesity [6].

In Portugal, antibiotic consumption was for a long time listed above the average registered in Europe, despite its decreasing tendency that had stabilised after 2006. Regarding antibiotic consumption in hospitals, it quantitatively represents only a small share of the national total, with its predominance being in outpatient care. This area of consumption gains relevance given the fact that hospitals are where large spectrum antibiotics, the main ones responsible for selective pressure and consequent resistance development, are more often used [2].

Attending to the importance of this subject, a project named Antibiotic Resistance and Prescribing in European Children was created to maintain a data collection about worldwide surveillance of antimicrobial usage in children and neonates admitted to European hospitals. This study attempts to correlate numerous parameters with antibiotic incidence in children younger than six years old, highlighting the family's social and economic status, existence of chronic illness and possible prescription miscarriage [7]

Previous studies did not quantify the real exposure to antibiotics in children less than 6 years of age in this same area of work, which turns out to be a great opportunity to explore the warning call made by international scientific reports which were made with the intent of exposing the need of prioritizing rational prescription in paediatrics $[8,9]$.

\section{Methods}

\section{Study design and sample}

We performed a data analysis based on questionnaire responses by parents, which were delivered among several kindergartens and pre scholar institutes, both public and private. Throughout this study, keeping the homogeneity of the population was one of our primary concerns, in order to avoid possible bias. This project took place between December 2015 and May 2016, in the metropolitan area of Oporto, Portugal.

Regarding the age range, only children born after 2010 were included in this population study.

The majority of the questions were developed with the intention of preventing miscarriage of information and the responses were equally categorized. Additionally, the questionnaires were drafted based on previous study models and adapted to the targeted public.

Furthermore, our analysis included the observation of the influence of chronic diseases in antibiotic exposure and how far it could bias this study, since it is intimately related with more diagnosed pathologies.

This inquiry was anonymous and randomized among parents.

\section{Variables}

The following variables were registered: parent's age at the time of the child's birth (years), social economical features, number of children per couple, children's age, exposure to antibiotics before 6 years of age, frequency of usage and used antibiotic, body system (e.g. respiratory, urinary, etc.) most prompt to its necessity, presence of diagnosed chronic disease and affected system, prescribing entity (e.g. medical doctor or other), average of intake per year, number of times of usage during the child's lifetime, cessation of treatment (before its programed end) and reason for its termination.

\section{Outcome}

Our primary outcome was to analyse the incidence of antibiotics exposure in children less than 6 years of age.

\section{Statistical analysis}

The statistical analysis was performed using IBM SPSS statistics version 22 .

Categorical variables are presented as frequency and percentage and continuous variables as mean and standard deviation (SD).

For comparison among groups, the t-student's test was used for continuous variables; the chi-squared test was used for categorical variables.

The non-parametric Spearman test was used to compare the cessation of treatment and average of intake per year, as well as the eldest child's age and number of times during the studied child's life.

A p-value $<0.05$ was considered to be statistically significant.

\section{Results}

Upon reception of the questionnaires, a total of 1031 inquiries were validated (a sample that includes more than 10\% of the studied population; a required criterion for its representativeness).

The percentage of children exposed to antibiotic therapy less than 6 years old was $92.6 \%$ (Figure 1).

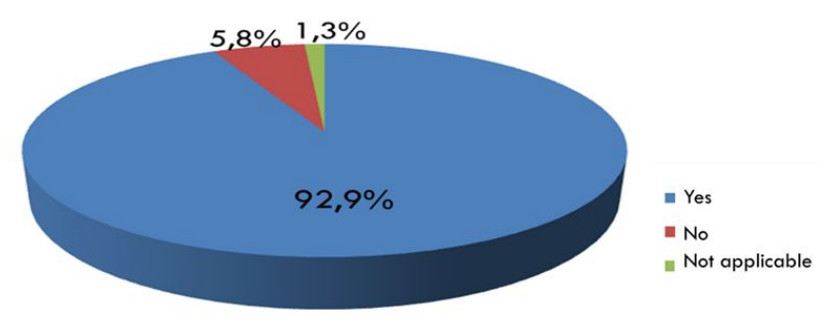

Figure 1: Antibiotic incidence in the study population.

Parent's age ranged between 15 and 53 years old, with a mean of 31 years old. Regarding parent's professions, $79.2 \%$ were not related to health services. A balance of the parent's academic level was observed. The average of children per parent inquired was 1.58 . Chronic diseases were absent in $90.9 \%$ and when present were mostly related with the respiratory system (48.5\%). The most common prescribing entity observed was a medical doctor $(98.2 \%)$.

$78.5 \%$ of the studied children had an antibiotic intake of 1-2 times per year, with an average of 4 till the present age.

Concerning cessation of treatment, $94 \%$ comply with the prescription made by the physician. When terminated earlier, $45 \%$ were due to favourable evolution of the symptoms and $49 \%$ by medical recommendation.

Otorhinolaryngology was the area where most of the cases of exposure to antibiotics were stated, followed by the respiratory system. 
Citation: Machado HS, Marafona AS, Meireles JP, Nunes CS, Esteves AL, et al. (2016) The Incidence of Exposure to Antibiotics in Children Less Than 6 Years of Age: A Survey in a Portuguese Metropolitan Area. J Preg Child Health 3: 292. doi:10.4172/2376-127X.1000292

Page 3 of 4

The viral infection conditions were observed as "requiring" antibiotic therapy in $8 \%$ of the cases (Table 1 ).

\begin{tabular}{|l|l|l|}
\hline Organic System & Frequency & Percentage \\
\hline Respiratory & 322 & $25.00 \%$ \\
\hline Urinary tract & 73 & $5.70 \%$ \\
\hline Gastrointestinal tract & 17 & $1.30 \%$ \\
\hline Skin & 30 & $2.30 \%$ \\
\hline Otorhinolaryngology & 718 & $55.70 \%$ \\
\hline Ophthalmology & 19 & $1.50 \%$ \\
\hline Viral & 106 & $8.20 \%$ \\
\hline Other & 3 & $0.20 \%$ \\
\hline Total & 1288 & $100 \%$ \\
\hline
\end{tabular}

Table 1: Type of infections in the study population.

The data revealed that amoxicillin-clavulanic acid, commercialized as Clavamox", was the most used antibiotic in the studied population (Table 2).

\begin{tabular}{|c|c|c|}
\hline Antibiotic & Frequency & Percentage \\
\hline $\begin{array}{l}\text { Amoxicillin+clavulanic } \quad \text { acid } \\
\left(\text { Clavamox }^{\circledR}\right)\end{array}$ & 673 & $54.70 \%$ \\
\hline Azithromycin & 84 & $6.80 \%$ \\
\hline Cefuroxime & 23 & $1.90 \%$ \\
\hline $\begin{array}{l}\text { Amoxicillin+clavulanic } \quad \text { acid } \\
\left(\text { Augmentin }{ }^{\circledR}\right)\end{array}$ & 130 & $10.60 \%$ \\
\hline Flucloxacillin & 11 & $0.90 \%$ \\
\hline Cefaclor & 35 & $2.80 \%$ \\
\hline Clarithromycin & 39 & $3.20 \%$ \\
\hline Cefixime & 13 & $1.10 \%$ \\
\hline Erythromycin & 9 & $1 \%$ \\
\hline Other & 214 & $17.40 \%$ \\
\hline Total & 1231 & $100 \%$ \\
\hline
\end{tabular}

Table 2: Prescribed antibiotics in the study population.

Our statistical study revealed significant associations between a number of variables: cessation of treatment and number of times of usage during the child's lifetime $(\mathrm{p}<0.05)$ (Table 3$)$; cessation of treatment and average intake per year $(\mathrm{p}=0.021)$; presence of diagnosed chronic disease and number of times of usage during the child's lifetime $(\mathrm{p}=0.02)$ (Table 4); eldest child's age and cessation of treatment $(\mathrm{p}=0.018)$ (Table 5); eldest child's age and number of times of usage during the child's life ( $\mathrm{p}=0.014)$.

\begin{tabular}{|l|l|l|l|l|l|}
\hline & $\begin{array}{l}\text { Cessation } \\
\text { of } \\
\text { treatment }\end{array}$ & $\mathbf{N}$ & $\begin{array}{l}\text { Mea } \\
\mathbf{n}\end{array}$ & $\begin{array}{l}\text { Standar } \\
\mathbf{d} \\
\text { deviatio } \\
\mathbf{n}\end{array}$ & $\begin{array}{l}\text { Standard } \\
\text { mean error }\end{array}$ \\
\hline
\end{tabular}

\begin{tabular}{|l|l|l|l|l|l|}
\hline $\begin{array}{l}\text { Number of times } \\
\text { of usage during } \\
\text { the child's lifetime }\end{array}$ & No & $4600.00 \%$ & 2,30 & 1,685 & 0,248 \\
\hline & Yes & $\begin{array}{l}61200.00 \\
\%\end{array}$ & 4,48 & 3,972 & 0,161 \\
\hline
\end{tabular}

Table 3: Statistical description of related variables: Number of times of usage during the child's lifetime and cessation of treatment.

\begin{tabular}{|l|l|l|l|l|l|}
\hline & $\begin{array}{l}\text { Child with } \\
\text { chronic illness }\end{array}$ & $\mathbf{N}$ & $\begin{array}{l}\text { Mea } \\
\mathbf{n}\end{array}$ & $\begin{array}{l}\text { Standar } \\
\mathbf{d} \\
\text { deviatio } \\
\mathbf{n}\end{array}$ & $\begin{array}{l}\text { Standar } \\
\mathbf{d} \text { mean } \\
\text { error }\end{array}$ \\
\hline $\begin{array}{l}\text { Number of times } \\
\text { of usage during } \\
\text { the child's lifetime }\end{array}$ & No & 616 & 4,10 & 3,523 & 0,142 \\
\hline & Yes & $\begin{array}{l}4600.00 \\
\%\end{array}$ & 7,33 & 6,542 & 0,965 \\
\hline
\end{tabular}

Table 4: Statistical description of related variables: Number of times of usage during the child's lifetime and presence of diagnosed chronic illness.

\begin{tabular}{|l|l|l|l|l|l|}
\hline & $\begin{array}{l}\text { Ended } \\
\text { therapeutic } \\
\text { scheme? }\end{array}$ & N & Mean & $\begin{array}{l}\text { Standard } \\
\text { deviation }\end{array}$ & $\begin{array}{l}\text { Standard } \\
\text { mean error }\end{array}$ \\
\hline $\begin{array}{l}\text { Age of the } \\
\text { eldest child } \\
\text { per couple }\end{array}$ & No & 54 & $\begin{array}{l}51,48 \\
1\end{array}$ & $2,98,049$ & 0,40559 \\
\hline & Yes & $\begin{array}{l}89400.00 \\
\%\end{array}$ & $\begin{array}{l}61,92 \\
4\end{array}$ & $4,29,347$ & 0,14360 \\
\hline
\end{tabular}

Table 5: Statistical description of related variables: age of the eldest child per couple and therapeutic scheme completion.

\section{Discussion}

The core question of this study focused on the incidence of antibiotic exposure. According to the collected data, over $90 \%$ of children under six years old had already been in contact with this type of medication. This elevated percentage meets our initial prospects. However, given the actual global concern about this subject and implemented programmes, which aim to decrease the levels of antibiotic usage at an early age, a lower ratio of consumption would be expected in our study population.

A possible association between the literacy level of the parents or one of them being a health care practitioner, with the frequency of antibiotic therapy was tested, but revealed it inconclusive. These variables were tested with the intent to recognise the importance of academic knowledge on the matter of antibiotic usage as well as a possible self-medication situation, from parents to children.

Attending to the current Portuguese legislation, a medical doctor prescription is the only legal way of getting this type of drugs; our data showed that the majority $(98 \%)$ of subjects received antibiotic prescription from the physician and not from other entities.

Since otorhinolaryngology plays a major role in the most current pathologies affecting children within the age range covered in this study [10], our prediction was that it would represent the most 
common area of antibiotic prescription, which proved to be accurate. The next most prominent cause of antibiotic prescription was the respiratory system.

The third cause of antibiotic prescription was a viral disease; this fact emerged as an unforeseen result since its major clinical characteristic is its self-limited behaviour, and no clinical support exists for this prescription in these types of infection conditions. Therefore, it was vital to recognise the importance of the viral component, which was seen in about $8 \%$ of the studied cases, in order to quantify this as a problem. In self-limited conditions, as referred above, antibiotic therapy is not advised, its treatment consisting in symptomatic management and some preventive measures due to its spread range.

The notorious increase in resistance to antibiotics embodied our main concern when approaching the core question of antibiotic exposure. A significant relation was encountered between the variables that aimed to quantify the interruption of treatment and the number of times of antibiotic usage in the first six years of childhood. It was perceived that children who interrupted the treatment had an average exposure of 2.3 times in the first six years of life as opposed to infants who completed the therapeutic scheme and presented twice the times of antibiotic use. This fact may be explained by a greater awareness and propensity to resort to public health services, which may prove as an imperative concern by leading to over-prescription.

Therefore, if we associate a higher number of times of antibiotic prescription to a decrease in their ability to cure the targeted infection, then, the main issue turns out to be an excess of antibiotic use followed by a greater chance of antibiotic resistance.

As anticipated, an association between children with chronic conditions and the antibiotic exposure was confirmed, probably associated with their susceptibility to infection and their regular health monitoring.

Furthermore, couples with older children revealed a great antibiotic intake completion by their younger child (as prescribed), as well as a slightly higher exposure to antibiotics. Thus, parents with older children appear to be more informed about how to deal with an antibiotic prescription.

Regarding this previous relation, another possible link would be the number of children per couple associated with a higher antibiotic therapy. Our forethought was that this association would be corroborated, considering the experience of parents and their acquired knowledge related to antibiotic practise in paediatric population and its implications. Still, no significant association was observed.

\section{Limitations}

One of the most defying features of this study was to find the adequate number of inquiries necessary to build a representative sample of the population.

There was a weak response from numerous educational institutions (average of $25 \%$ replies out of all contacts) as well as from parents due to lack of time or understanding of the questionnaire or difficulty in recalling past events regarding the approached topic.

Since our inquiry was not designed to recognize viral disease features, our study outcomes may underestimate the association of viral disease and antibiotic use.

\section{Conclusion}

In our study, a high incidence of antibiotic exposure in the less than six years of age was observed which emphasized the importance of our core question.

Significantly, there appears to be an association between compliance with the antibiotic therapeutic scheme and a higher frequency of antibiotic intake as well as between this and presence of chronic illness.

Furthermore, the age of a couple's eldest child seems to be correlated with a better compliance with the treatment, by their younger brothers/sisters, with a slightly higher frequency of antibiotic usage.

In conclusion, and given the relevance of the approached topic, further studies should be conducted in order to clarify the underlying connection between antibiotic over-prescription and misuse in viral infections and the emergence of resistant bacterial strains.

\section{Acknowledgement}

The authors would like to thank all the educational institutions that agreed to participate in this study as well as the teachers and parents for their cooperation in the distribution and filling out of the questionnaires.

\section{References}

1. Ligon BL (2004) Penicillin: Its discovery and early development. In seminars in pediatric infectious diseases 15: 52-57.

2. Fernandes PA, Silva MG, Cruz AP, Paiva JA (2015) Program for the prevention and control of infections and resistance to antimicrobials in numbers. Directorate-General for Health.

3. Segal Z, Cohen MJ, Engelhard D, Tenenbaum A, Simckes AM, et al. (2016) Infants under two months of age with urinary tract infections are showing increasing resistance to empirical and oral antibiotics. Acta Paediatrica 105: e156-60.

4. Bryce A, Hay AD, Lane IF, Thornton HV, Wootton M, et al. (2016) Global prevalence of antibiotic resistance in paediatric urinary tract infections caused by Escherichia coli and association with routine use of antibiotics in primary care: Systematic review and meta-analysis. BMJ 352-939.

5. Korpela K, Salonen A, Virta LJ, Kekkonen RA, Forslund K, et al. (2016) Intestinal microbiome is related to lifetime antibiotic use in Finnish preschool children. Nature communications 7: 10410.

6. Azad MB, Bridgman SL, Becker AB, Kozyrskyj AL (2014) Infant antibiotic exposure and the development of childhood overweight and central adiposity. International Journal of Obesity 38: 1290-1298.

7. Versporten A, Sharland M, Bielicki J, Drapier N, Vankerckhoven V, et al. (2013) The antibiotic resistance and prescribing in European children project: A neonatal and pediatric antimicrobial web-based point prevalence survey in 73 hospitals worldwide. The Pediatric Infectious Disease Journal 32: 242-253.

8. Neville KA, Frattarelli DA, Galinkin JL, Green TP, Johnson TD, et al. (2014) Off-label use of drugs in children. Pediatrics 133: 563-567.

9. Murphy JL, Fenn N, Pyle L, Heizer H, Hughes S, et al. (2016) Adverse events in pediatric patients receiving long-term oral and intravenous antibiotics. Hospital Paediatrics 6: 330-338.

10. Machado ACS, Manso JA, Xavier JB, Estrada JF, Silva LCJ, et al. (2009) National commission for child and adolescent health 2004-2008. Portuguese society of pediatrics, Lisbon: High commission for health. 